Supplement of The Cryosphere, 14, 4611-4626, 2020

https://doi.org/10.5194/tc-14-4611-2020-supplement

(C) Author(s) 2020. This work is distributed under

the Creative Commons Attribution 4.0 License.

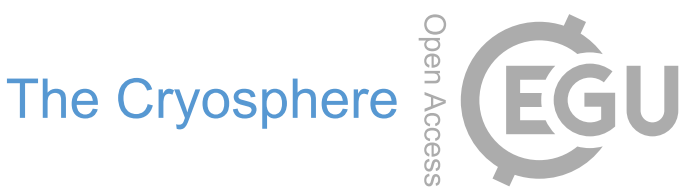

(c) (1)

Supplement of

\title{
Projecting circum-Arctic excess-ground-ice melt with a sub-grid representation in the Community Land Model
}

Lei Cai et al.

Correspondence to: Lei Cai (leca@norceresearch.no)

The copyright of individual parts of the supplement might differ from the CC BY 4.0 License. 


\section{S1. The sensitivity of excess ice melt and corresponding impacts to its sub-grid distribution}

We design idealized single-grid simulation cases, aiming to examine the effects of incorporating excess ice at the sub-grid scale to soil physics, i.e. whether different sub-grid scale distributions of excess ice differ reasonably from each other during excess ice melt. The results of single-grid simulations help to verify if the subgrid representation of excess ice shows more potential in modeling excess ice compared to its previous version, where excess ice is homogeneously distributed in the CLM grid cell (Lee et al., 2014). We employ the forcing data at the North Slope of Alaska (NSA; 70 $\mathrm{N}, 156^{\circ} \mathrm{W}$ ) and to the Northeast of Yakutsk (Yakutsk; $63^{\circ} \mathrm{N}, 130^{\circ}$ E) to represent the continental and maritime types of climate respectively in the circum-Arctic. They have the annual mean temperature and precipitation close to each other, while the seasonal variability in temperature is smaller in the North Slope of Alaska due to its adjacency to the Arctic Ocean (Bieniek et al., 2012).
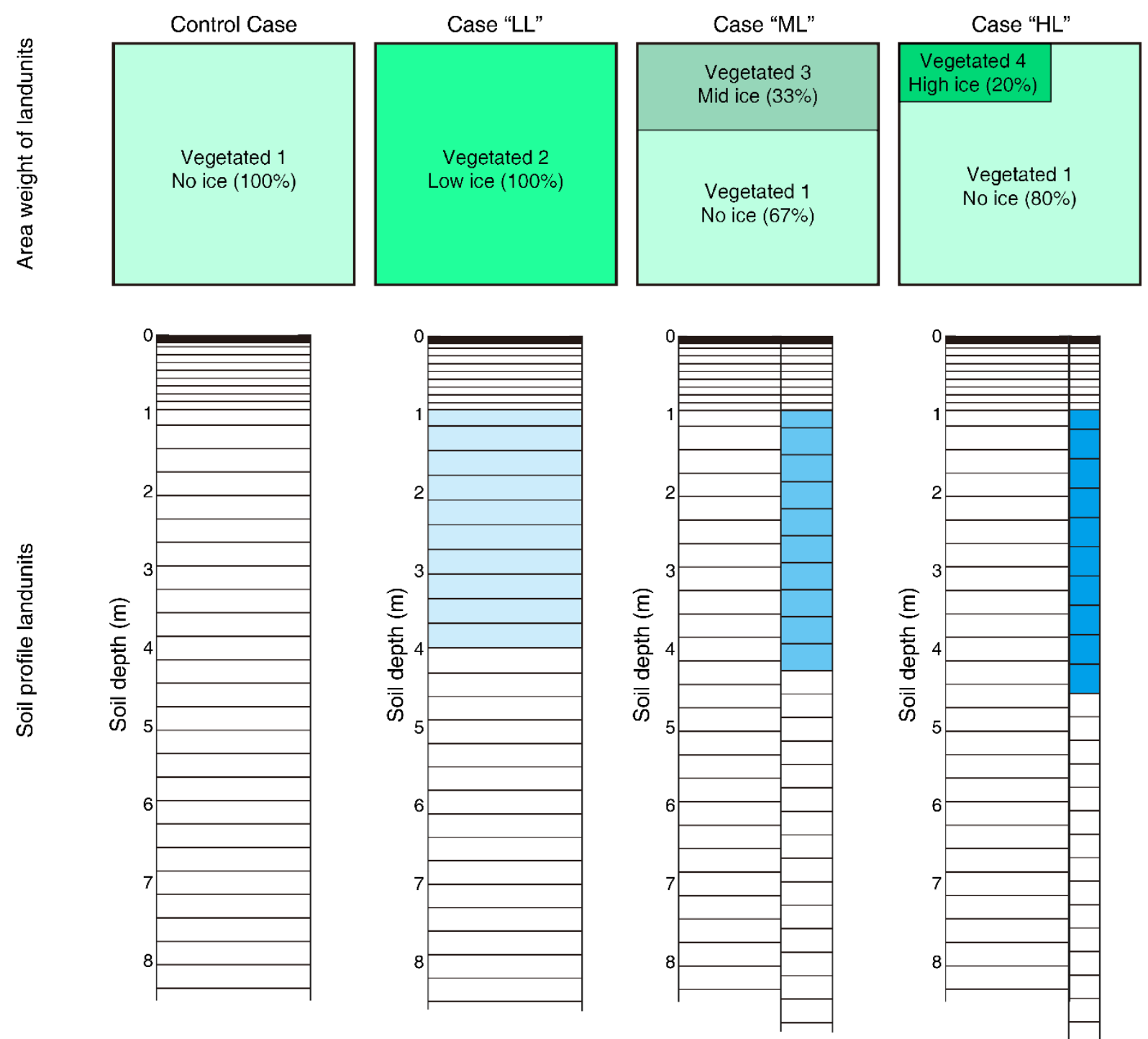

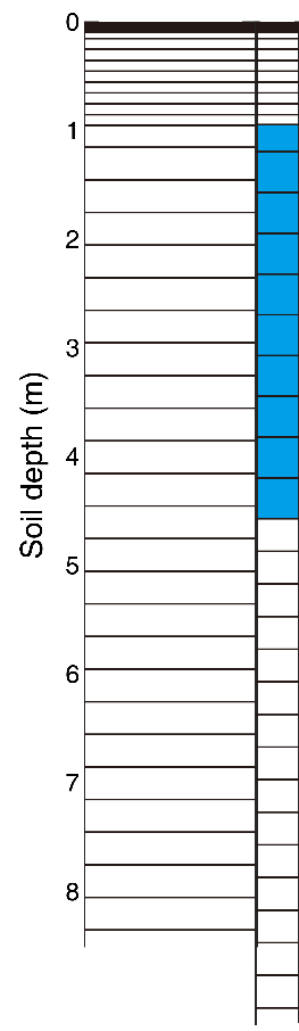

$25 \%$ excess ice 
Figure S1: The schematic figure for the area weights (the percentage between parentheses) and soil profiles within the landunits in the four single-grid simulations. Besides the control case, three other cases are with the same amount of excess ice within the single grid. "LL", "ML", and "HL" are abbreviations for "Low ice Landunit", "Mid ice Landunit", and "High ice Landunit", representing the applied excess ice landunit in each case.

The grid-mean volumetric excess ice content is set to be 5\%. We set up three excess ice cases with the same (or very close) grid-scale excess ice content but with different spatial variability. For each site, we design three cases, having a 100\% area weight of 5\% volumetric excess ice content (NSA_LL and Yakutsk_LL), a 33\% area weight of $15 \%$ volumetric excess ice content (NSA_ML and Yakutsk_ML), and a 20\% area weight of 25\% volumetric excess ice content (NSA_HL and Yakutsk_HL), respectively (Figure S1). For all of the original soil layers between 1-4 meters, excess ice is incorporated homogeneously, which proportionally increases the soil thickness for these layers. The initialization depth of excess ice keeps the same as in Lee et al. (2014). Both locations we choose are with $100 \%$ natural soil and continuous permafrost to avoid the interference of model results by other landunit types from the source.

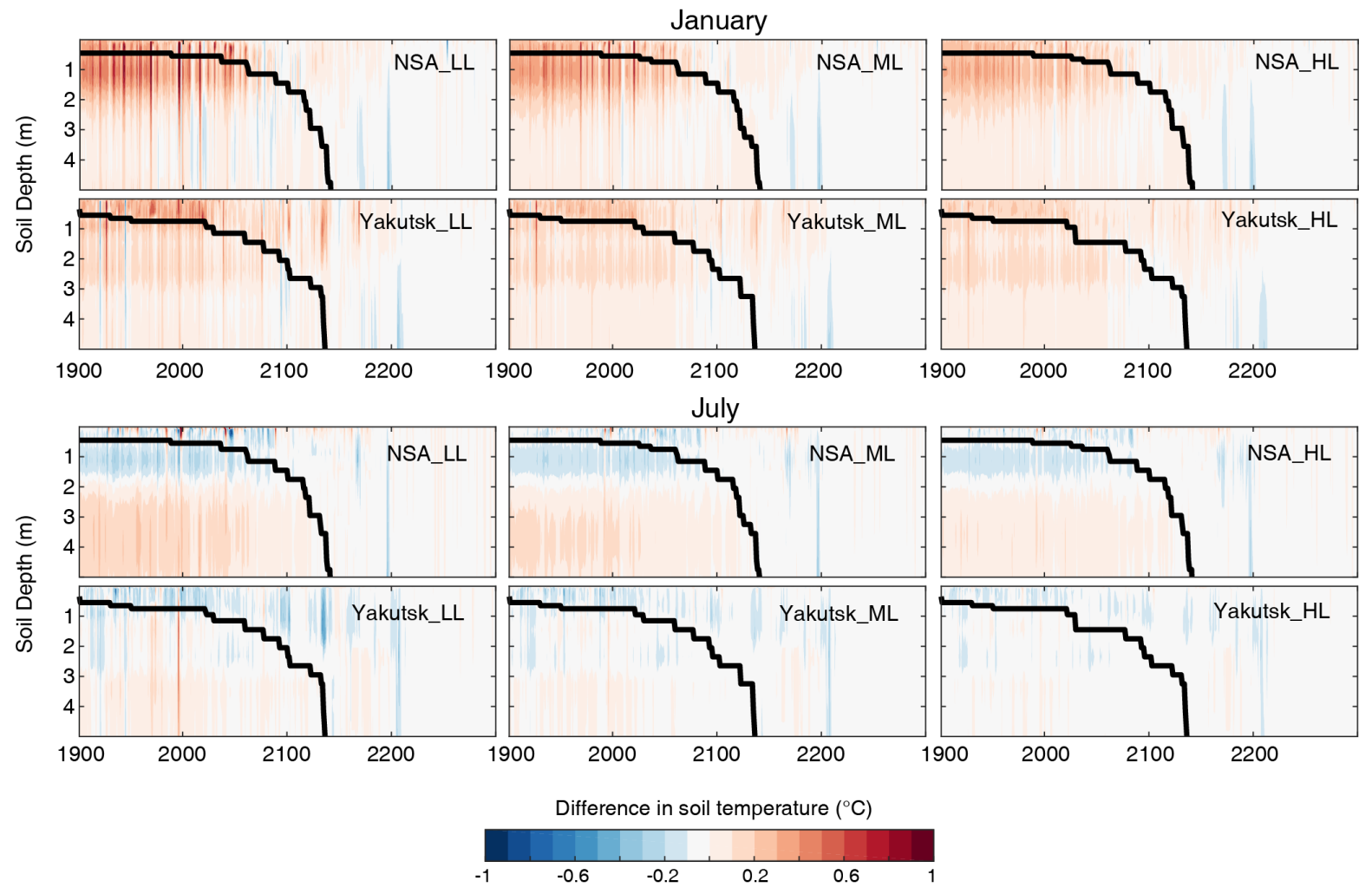

Figure S2: Soil temperature differences from excess ice cases to control cases (NSA_control and Yakutsk_control) for the depth of 0.005-5 meters in January and July. Black lines are the active layer depth deepening through time. The active layer depth is calculated from grid-scale soil temperature for each case. 


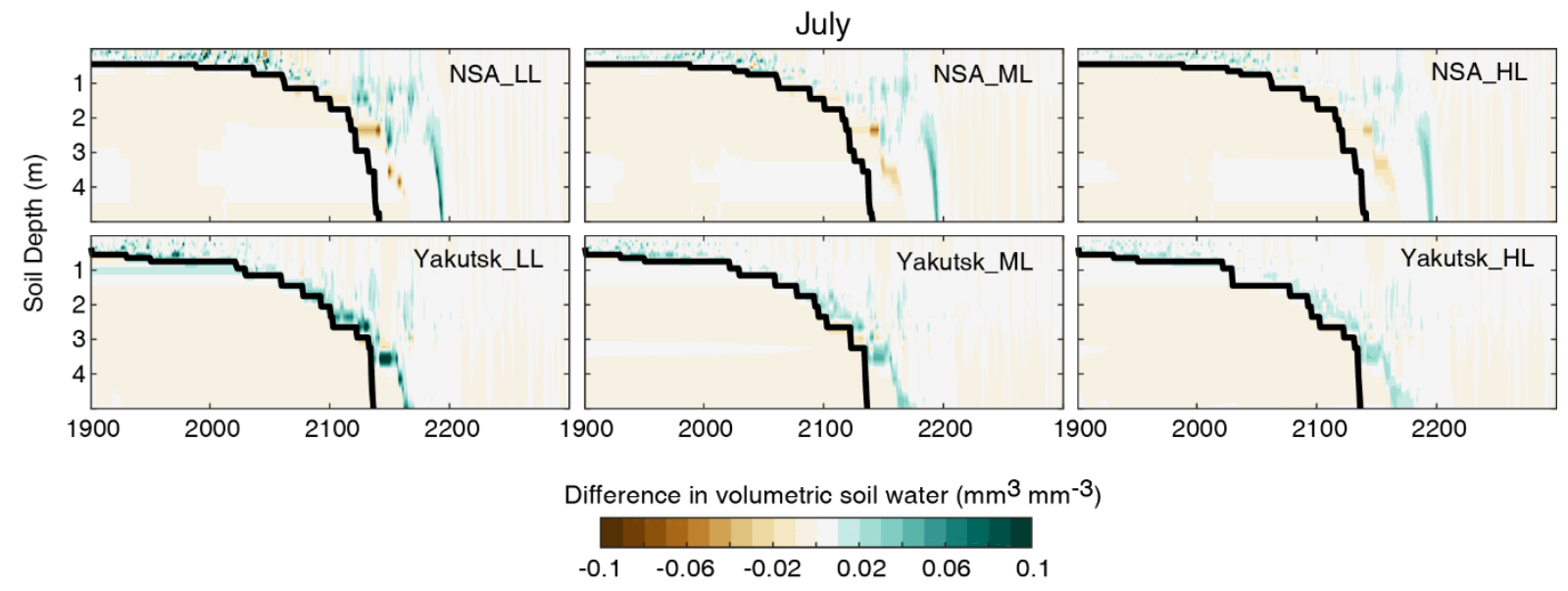

Figure S3: Soil moisture differences from excess ice cases to the corresponding control cases (NSA_control and Yakutsk_control) for the depth of 0.05-5 meters in July. Black lines are the active layer depth deepening through time. The active layer depth is calculated from grid-scale soil temperature for each case.

As a result, differences in soil temperature and moisture from excess ice cases to control cases in single-grid simulations quantitatively show the effects of excess ice and its melting. In the shallower layers (0-2 m), excess ice results in slightly higher soil temperature in January (winter) but lower soil temperature in July (summer) relative to control cases, reducing the magnitude of the seasonal cycle in soil temperature (Figure S2). In deeper layers $(>2 \mathrm{~m})$, the soil temperature in excess ice cases remains higher compared to control cases for both in summer and winter. The above responses in permafrost temperature results from the increases of specific heat and thermal conductivity of the soil layer after incorporating excess ice. As the climate warms and permafrost thaws, the meltwater discharges in the form of runoff, eventually bringing soil temperatures in excess ice cases closer to that in the control case. For soil moisture, the volumetric water content in July is higher in excess ice cases than control and is just above the permafrost table (Figure S3). As the active layer substantially deepens in the projected period for both sites, soil water in excess ice cases increases abruptly around 2180 for NSA while around 2150 for Yakutsk, indicating the degradation of permafrost in control cases. When permafrost degrades in the control case, the excess soil water in control cases starts to runoff in the form of subsurface drainage, flushing out soil water and making the soil drier. Note that the subsurface drainage is unlikely to happen in reality since the permafrost at these two sites are much thicker than $10 \mathrm{~m}$. Meanwhile, this has not occurred in excess ice cases yet, making the soil wetter in excess ice cases than in control cases. These responses in permafrost temperature and moisture after permafrost degradation are consistent with the results in Lee et al. (2014), suggesting that the excess ice physics developed in CLM4.5_EXICE performs reasonably in a sub-grid manner in CLM5. Among the three excess ice cases, the "LL" case shows the strongest responses in both soil temperature and soil water content. On the other hand, the effects of excess ice in soil temperature and moisture are weaker in the "ML" and "HL" cases, where the same amount of excess ice is distributed more localized within a fraction of the grid.

Both sites exhibit active layer depth of around $0.5 \mathrm{~m}$ by the end of the spinup and active layer thickness does not increase substantially during the historical period (Black lines in Figure S2 and S3). For this reason, excess ice is incorporated one meter below the surface. No excess ice, therefore, melts during either the spin-up or the historical period simulations. Excess ice starts to melt around the 2070s in NSA_LL, while the timing is delayed 
for about 25 years in the other two cases for the same site (NSA_ML and NSA_HL; Figure S4). It is because the higher content of excess ice covering a smaller area takes longer to absorb enough latent heat of fusion from the atmosphere before it can start melting. Excess ice in NSA completely melts away in the 2170s and the exact timing of which varies slightly ( $<5$ years) between cases. In Yakutsk, excess ice starts to melt earlier, but with a slower rate compared to NSA. Similar to the NSA cases, Yakutsk_ML and Yakutsk_HL exhibit delays in the timing of excess ice melt compared to Yakutsk_LL. Excess ice in Yakutsk_LL completely melts in the 2170s, while the timings of excess ice melting in Yakutsk_ML and Yakutsk_HL is delayed for about 10 to 15 years, respectively (Figure S4).

Excess ice melting supplies extra water to subsurface water storage, increasing soil water and eventually converting to runoff. The increases in surface runoff correspond well in timing with excess ice melt (Figure S4). Earlier permafrost thaw timing in control cases causes an earlier increase in subsurface runoff and a decrease in the surface runoff than in excess ice cases. On the other hand, when the active layer depth reaches below the deepest soil layer in excess ice cases, more soil water from melt ice leads to the higher subsurface runoff compared to that in control cases. Among the three excess ice cases, the "LL" cases consistently exhibit the strongest and earliest responses in both surface and subsurface runoff as excess ice melts, being consistent with their earlier start of excess ice melt. 

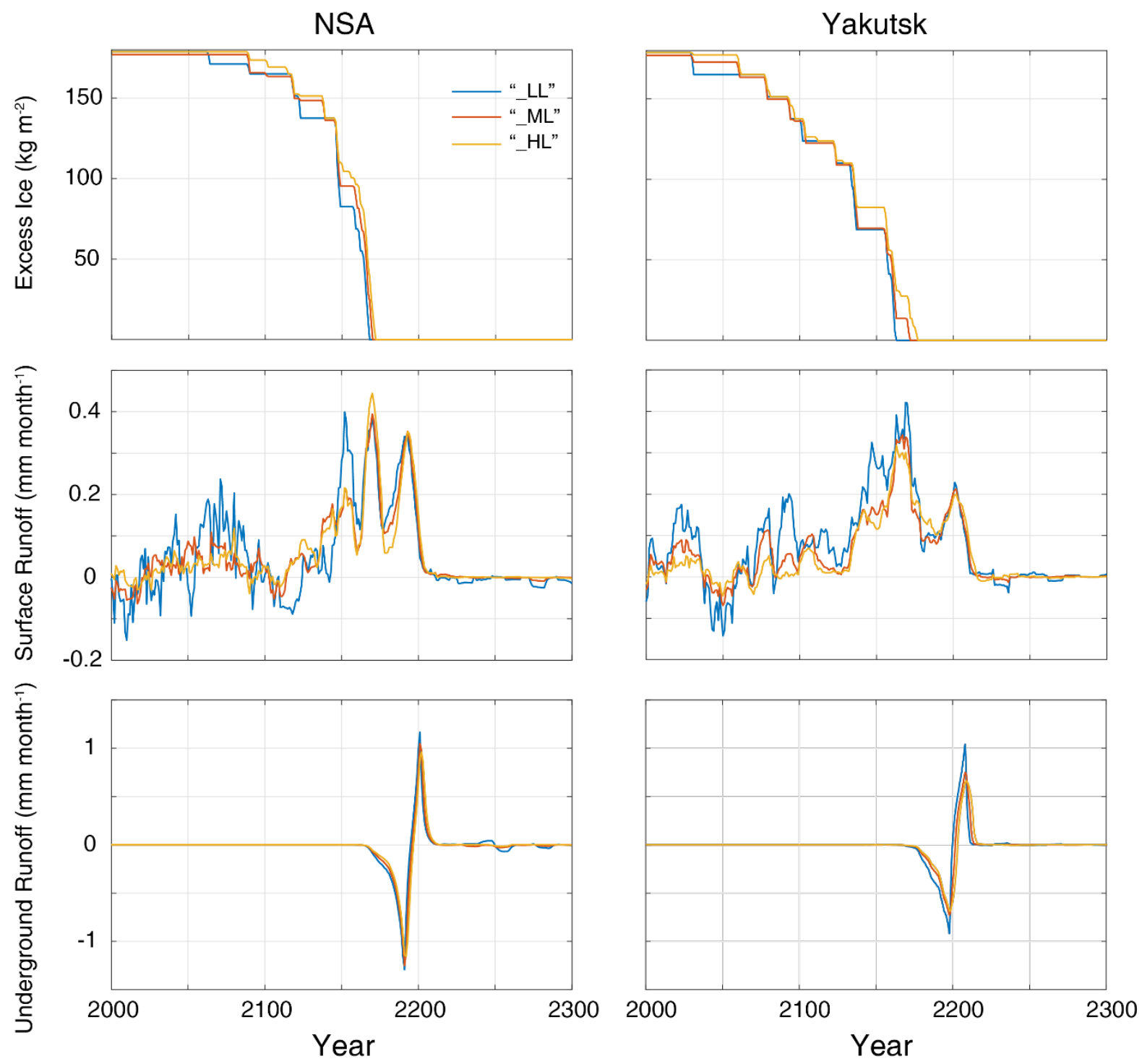

Figure S4: Time series of excess ice $\left(\mathrm{kg} \mathrm{m}^{-2}\right)$, as well as the difference of surface runoff (mm month $\left.{ }^{-1}\right)$ and subsurface drainage ( $\mathrm{mm} / \mathrm{month}$ ) from the three excess ice cases to control cases. A 15-year moving average is applied before plotting both the surface and underground runoff.

\section{References}

Bieniek, P. A., Bhatt, U. S., Thoman, R. L., Angeloff, H., Partain, J., Papineau, J., Fritsch, F., Holloway, E., Walsh, J. E., Daly, C., Shulski, M., Hufford, G., Hill, D. F., Calos, S., and Gens, R.: Climate Divisions for Alaska Based on Objective Methods, Journal of Applied Meteorology and Climatology, 51, 1276-1289, 10.1175/jamc-d-11-0168.1, 2012.

Lee, H., Swenson, S. C., Slater, A. G., and Lawrence, D. M.: Effects of excess ground ice on projections of permafrost in a warming climate, Environmental Research Letters, 9, 124006, 2014. 
